\author{
Olga SOROCZAN ${ }^{1}$ \\ Diana IGNATIUK ${ }^{2}$
}

\title{
ЭКОНОМИЧЕСКАЯ БЕЗОПАСНОСТЬ: СОСТОЯНИЕ И УГРОЗЫ В РЕСПУБЛИКЕ МОЛДОВА
}

\begin{abstract}
Для стран с переходной экономикой проблема экономической безопасности стоит с наибольшей остротой. Экономическая безопасность рассматривается нами как способность национальной экономической системы к эффективному и устойчивому развитию. Понятие угрозы является ключевым в концепции экономической безопасности. Вероятность возникновения угроз, а также степень их интенсивности определяется при помощи особых индикаторов - nороговых значений экономической безопасности. Исходя из основных стандартов параметров безопасности, принятых в мировой практике и ЕС, в статье проведен сравнительный системный анализ состояния реального сектора экономики Республики Молдова и представлены рекомендации по нейтрализации существующих угроз.

Ключевые слова: безопасность, угроза, институты власти, индикаторы безопасности, национальная экономическая система, продовольственная независимость.
\end{abstract}

На протяжении всей истории человеческой цивилизации потребность в безопасности выступает одной из ключевых потребностей и отдельного человека, и общества в целом.

В XXI в. проблема обеспечения национальной безопасности приобрела особую актуальность. Можно выделить целый ряд факторов, которые способствовали данному обстоятельству: динамизм и непредсказуемость общественного развития, стремительный научно-технический прогресс, нарастание и усложнение взаимосвязей и взаимозависимости экономик различных стран, обострение международной конкуренции, возрастание глобальных угроз и факторов риска для жизнедеятельности людей. Все это требует особого внимания в политических, деловых, научных кругах к проблеме безопасности страны в целом и её основе - экономической безопасности. Защита национальной экономики от воздействия внутренних и внешних угроз, а также поиск эффективных способов повышения уровня национальной и экономической безопасности становятся приоритетными направлениями при разработке стратегий социально-экономического развития современных государств.

Для стран с переходной экономикой, которые отличаются высокой неустойчивостью и противоречивостью социально-экономического развития, сложными процессами

${ }^{1}$ Prof. dr hab. Olga Soroczan, dr hab., Katedra Ekonomicznych Teorii i Polityki Mołdawskiej Ekonomicznej Akademii.

${ }^{2}$ Diana Ignatiuk, Katedra Ekonomicznych Teorii i Polityki Mołdawskiej Ekonomicznej Akademii. 
активного вовлечения в современные мирохозяйственные связи, проблема экономической безопасности стоит с наибольшей остротой.

Несмотря на многочисленные исследования данной темы специалистами в области политики, экономики, социологии, права, на данный момент не сложилась общепринятая трактовка понятия «экономическая безопасность». В научной литературе существует большое количество определений экономической безопасности, которые, как правило, основываются на самых общих характеристиках данной категории, не затрагивая глубоких причинно-следственных взаимосвязей в хозяйственной жизни. Весьма популярны следующие характеристики экономической безопасности:

- состояние экономики и институтов власти, при котором обеспечиваются гарантированная защита национальных интересов, социальная направленность политики, достаточный оборонный потенциал ${ }^{3}$;

- состояние, в котором народ может суверенно, без вмешательства и давления извне, определять пути и формы своего экономического развития ${ }^{4}$;

- способность экономики обеспечивать эффективное удовлетворение общественных потребностей ${ }^{5}$;

- целостность условий и факторов, которая обеспечивает независимость, стабильность и

- способность постоянного обновления и усовершенствования национальной экономики ${ }^{6}$.

На основании критического анализа существующих научных трактовок экономической безопасности нам представляется целесообразным синтезирующий подход, обеспечивающий комплексную характеристику данного феномена. На наш взгляд, экономическая безопасность - это способность национальной экономической системы к эффективному и устойчивому развитию. Ее достижение означает создание иелостной и независимой национальной экономики, обеспечивающей защиту социиально - экономических интересов нации и устойчивой $\kappa$ влиянию дестабилизирующих внутренних и внешних факторов (угроз).

Понятие угрозы является ключевым при определении экономической безопасности. Угрозы по своей сути представляют совокупность условий и факторов, оказывающих дестабилизирующее влияние на функционирование и развитие экономической системы. Перечень угроз весьма разнообразен. Принято выделять угрозы внешние и внутренние; угрозы, касающиеся отдельных отраслей и видов деятельности; реальные и потенциальные угрозы (в зависимости от вероятности их реализации).

ЗЭкономическая безопасность. - М.: ЗАО Финстатинформ., - 1998. - С. 12.

4 Жандаров А. М., Петров А..А. Экономическая безопасность России: определения, гипотеза, расчеты //Безопасность. - 1994. - №3. - С.167.

5Архипов А. и др. Экономическая безопасность: оценки, проблемы, способы обеспечения //

Вопросыэкономики. - 1994. - №12. - С. 56.

6Абалкин Л. Экономическая безопасность России: угрозы и их отражение // Вопросы экономики. - 1994. №12. - C. 54. 
При оценке угроз, существующих для национальной экономики, важно владеть информацией о вероятности их возникновения и степени интенсивности. В этой связи необходимо использовать особые индикаторы - пороговые значения экономической безопасности. Пороговые (критические) значения характеризуют границы, за пределами которых экономика страны попадает в зону риска и опасностей, нарушающих ход общественного воспроизводства и вызывающих негативные разрушительные тенденции в национальной экономической системе.

Безусловно, пороговые значения экономической безопасности являются лишь расчётными ориентирами. Поэтому и те страны, в которых они не полностью соблюдаются, не перестают существовать и развиваться. Однако такое развитие сопровождается дополнительными трудностями и поиском путей выхода из неустойчивого, внутренне противоречивого, состояния национальной экономики.

Важно подчеркнуть, что наивысшая степень безопасности достигается при условии, что весь комплекс соответствующих показателей находится в пределах допустимых пороговых значений. При этом критическое значение одного показателя не должно достигаться в ущерб другого индикатора. Так, снижение инфляции до предельного уровня нельзя проводить за счет повышения безработицы сверх допустимого предела в $7 \%$; а сокращение дефицита бюджета до порогового значения не должно сопровождаться полным замораживанием государственных капиталовложений и снижением бюджетных расходов на социальные цели.

Определив пороговые значения экономических показателей безопасности можно выявить критические, «опасные» границы национального воспроизводства, за которыми экономике угрожают кризисные явления, падает конкурентоспособность на внешних и внутренних рынках, усиливается экспансия иностранного капитала, расцветает коррупция и криминал.

Каждая национальная экономика должна располагать собственной, адаптированной системой пороговых значений экономической безопасности, которая соответствовала экономической, социальной, политической, этнической специфике конкретного государства. При этом определение критического предела показателей экономической безопасности требует учёта целого ряда факторов и их взаимосвязей, поскольку отклонение одного индикатора от его допустимого значения не может достоверно отразить интенсивность рисков и угроз, сложившихся в рамках национальной экономики.

Ориентация на пороговые значения должна служить отправной базой при формировании стратегии обеспечения экономической безопасности государства в среднесрочной и долгосрочной перспективе. Постоянный мониторинг макроэкономических показателей на основе пороговых значений экономической безопасности позволяет своевременно осуществлять мероприятия по корректировке курса развития национальной экономики.

К сожалению, в Республике Молдова, молодом транзитивном государстве, в настоящее время еще не разработана стратегия и механизм обеспечения экономической безопасности, данная проблема рассматривается частично, лишь в контексте 
достижения национальной безопасности. В официальной статистике отсутствует апробированная система пороговых значений экономической безопасности страны.

Исходя из основных стандартов параметров безопасности, принятых в мировой практике и ЕС, нами проведен сравнительный системный анализ и дана оценка соответствующих макроэкономических показателей в Республике Молдова.

Таблица 1.Состояние основных параметров экономической безопасности Республики Молдова (2011 г.)

\begin{tabular}{|c|c|c|c|c|}
\hline & Показатели & $\begin{array}{l}\text { Пороговая } \\
\text { величина }\end{array}$ & $\begin{array}{l}\text { Фактическое } \\
\text { значение }\end{array}$ & $\begin{array}{l}\text { Соотношение } \\
\text { порогового и } \\
\text { фактического } \\
\text { значений }\end{array}$ \\
\hline 1 & $\begin{array}{l}\text { Объем ВВП на душу населения: } \\
50 \% \text { от среднего по странам } \\
\text { ЕС } \\
100 \% \text { от среднемирового }\end{array}$ & $\begin{array}{l}20548 \$ \\
11639 \$\end{array}$ & $1966 \$$ & $\begin{array}{l}0.09 \\
0.17\end{array}$ \\
\hline 2 & $\begin{array}{l}\text { Доля в промышленном } \\
\text { производстве обрабатывающей } \\
\text { промышленности }\end{array}$ & $70 \%$ & $84 \%$ & 1,2 \\
\hline 3 & $\begin{array}{l}\text { Доля машиностроения в } \\
\text { промышленном производстве }\end{array}$ & $20 \%$ & $1,7 \%$ & 0,09 \\
\hline 4 & Объемы инвестиций, \% к ВВП & $25 \%$ & $23,6 \%$ & 0,8 \\
\hline 5 & Затраты на оборону, \% к ВВП & $5 \%$ & $2,2 \%$ & 0,44 \\
\hline 6 & $\begin{array}{l}\text { Расходы на научные } \\
\text { исследования, } \\
\text { \% к ВВП }\end{array}$ & $2 \%$ & $0,4 \%$ & 0,2 \\
\hline
\end{tabular}




\begin{tabular}{|c|c|c|c|c|}
\hline 7 & $\begin{array}{l}\text { Доля населения, имеющего } \\
\text { доходы ниже } \\
\text { прожиточного минимума }\end{array}$ & $7 \%$ & $75 \%$ & 10,7 \\
\hline 8 & $\begin{array}{l}\text { Продолжительность жизни } \\
\text { населения }\end{array}$ & 70 лет & 69 лет & 0,98 \\
\hline 9 & $\begin{array}{l}\text { Разрыв между доходами } 10 \% \\
\text { самых высокодоходных групп и } \\
10 \% \text { самых } \\
\text { низкодоходных групп населения }\end{array}$ & 8 раз & 8 раз & 1 \\
\hline 10 & $\begin{array}{l}\text { Расходы на образование, \% к } \\
\text { ВВП }\end{array}$ & $10 \%$ & $7,9 \%$ & 0,79 \\
\hline 11 & $\begin{array}{l}\text { Уровень безработицы, } \\
\text { по методологии МОТ }\end{array}$ & $7 \%$ & $5,3 \%$ & 0,8 \\
\hline 12 & Уровень инфляции, за год & $20 \%$ & $7,4 \%$ & 0,37 \\
\hline 13 & $\begin{array}{l}\text { Объем внешнего долга, } \\
\% \text { к ВВП }\end{array}$ & $25 \%$ & $16,3 \%$ & 0,65 \\
\hline 14 & $\begin{array}{l}\text { Объем внутреннего долга, } \\
\text { \% к ВВП }\end{array}$ & $30 \%$ & $7,4 \%$ & 0,25 \\
\hline 15 & Дефицит бюджета, \% к ВВП & $5 \%$ & $2,5 \%$ & 0,5 \\
\hline
\end{tabular}




\begin{tabular}{|c|l|c|c|c|}
\hline 16 & $\begin{array}{l}\text { Доля внешних заимствований в } \\
\text { покрытии дефицита бюджета }\end{array}$ & $30 \%$ & $65 \%$ & 2,17 \\
\hline 17 & $\begin{array}{l}\text { Текущая потребность в } \\
\text { обслуживании и погашении } \\
\text { государственного долга, } \\
\text { \% к доходам бюджета }\end{array}$ & $25 \%$ & $6,5 \%$ & 0,26 \\
\hline
\end{tabular}

Составлено по данным: Мировой (http://search.worldbank.org/all?qterm=moldova), Статистический ежегодник Республики Молдова, 2011, стр.275, Годовой отчёт Национального Банка Молдовы, 2011, стр. 9-37 (http://www.lan.bnm.org/md/annual_report), Годовой отчёт Министерства Финансов Молдовы по вопросам публичного долга, государственных гарантий и государственного рекредитования, 2011 (http://mf.gov.md/ro/publicdebt/debt/reports)

Как свидетельствуют данные таблицы, состояние ключевых показателей экономической безопасности в Республике Молдова весьма неоднозначно. Более благоприятная ситуация просматривается по ряду индикаторов в сфере финансов (по уровням бюджетного дефицита, внутренней и внешней задолженности государства, инфляции).

Согласно официальным данным, в Молдове близки к стандартам такие параметры: продолжительность жизни населения, разрыв между доходами $10 \%$ самых высокодоходных групп населения и $10 \%$ самых низкодоходных групп. Вместе с тем угрожающий разрыв между пороговым и фактическим значением (почти в 11 раз!) наблюдается по индикатору «доля населения, имеющего доходы ниже прожиточного минимума», который свидетельствует о массовой бедности населения.

«Болевые точки» молдавской экономики сконцентрированы в ee малоэффективности и низкой конкурентоспособности, что наглядно отражают следующие показатели: сверхнизкий уровень ВВП на душу населения, мизерная доля в промышленном производстве машиностроения, символические затраты на науку. Отсталость реального сектора провоцирует наибольшие угрозы для национальной экономики. Остановимся на них подробнее.

Развитие производственного сектора в Республике Молдова не отличается устойчивым характером: положительная динамика (2000-2005 гг.) была вытеснена с 2006 г. неровной тенденцией спада. Самое существенное сокращение промышленного производства наблюдалось в 2009 г. (на 22,6\% по сравнению с предыдущим годом). Последующее увеличение объёма промышленной продукции (начиная с 2010г.) позволило лишь частично возродить промышленный сектор, однако уровень докризисного производства 2008г. в Республике Молдова не был достигнут. В целом 
объём промышленного производства за десятилетие (2000- 2010 гг.) увеличился всего на $35,8 \%$.

В качестве явной угрозы экономической безопасности выступает неравномерная географическая концентрация промышленного производства. Большая часть промышленного производства (57\% в 2010г.) сконцентрирована в столице Республики Молдова.

Значительное увеличение концентрации промышленного производства в столице происходило в последние годы, причем за счёт уменьшения числа функционирующих предприятий в других регионах страны. Данное обстоятельство отрицательно сказывается на состоянии рынка труда в большинстве регионов Молдовы, приводит к росту безработицы, к снижению уровня жизни и росту социальной напряжённости на периферии республики. Все эти процессы представляют реальные угрозы для национальной экономической безопасности.

Серьезное беспокойство вызывает и катастрофически низкий уровень машиностроения в общем объёме промышленного производства Молдовы - всего 1,7\% в 2011 г., что в 12 раз меньше предельно допустимого значения для долгосрочного и безопасного экономического роста. Такое состояние дел предопределяет ограниченные возможности предприятий по модернизации основных фондов, а также низкую конкурентоспособность национальной экономики в целом. Доля инвестиций в основной капитал в Молдове в 2011 г. составила 18,8\% ВВП, при пороговом значении данного показателя в $25 \%$.

Сложившаяся в Молдове структура промышленного производства также вызывает серьезные риски и угрозы для экономической безопасности страны. По «весу» в промышленном секторе доминирует обрабатывающая промышленность: ее доля в общем объёме промышленного производства составляет 84\%, что намного выше порогового значения (70\%). Однако эта отрасль национальной экономики является довольно уязвимой, чувствительной к влиянию глобального экономического кризиса. Так, в 2009г. снижение объёма производства в данной отрасли составило 22,8\% в сравнении с предыдущим годом.

Кроме того около $50 \%$ всей обрабатывающей промышленности в Молдове приходится на пищевую промышленность, которая чаще всего подвергается дестабилизирующему влиянию внешних и внутренних социально-экономических и политических факторов. Наглядным примером высокой чувствительности пищевой промышленности является значительное сокращение ее выпуска в 2006-2007 гг., после введения Россией ограничений на импорт из Молдовы алкогольных напитков и других продуктов питания. На состояние пищевой промышленности негативно влияют и ухудшающиеся с каждым годом климатические условия. Так, в 2007г. в результате засухи объём производства уменьшился на 40\%, а в 2012 г., согласно самым оптимистическим экспертным оценкам, уменьшение производства составило $35 \%$.

Отрасли агропромышленного комплекса в большинстве своём обеспечены собственным сырьём, поэтому в Республике Молдова получили достаточное развитие молочная, мясная, хлебобулочная, мукомольная, сахарная, консервная промышленность. 
Долгое время продукция этих отраслей практически полностью удовлетворяла потребности населения республики.

Длительные реформы АПК значительно изменили облик, структуру и эффективность функционирования важнейшего комплекса национальной экономики. На данный момент АПК страны представлен, в основном, мелкими фермерскими и личными крестьянскими хозяйствами, кооперативами различного уровня, а также мелкими и средними предприятиями обрабатывающей промышленности. Развитие рыночных отношений в сельском хозяйстве республики осуществляется с большими трудностями. К ним можно отнести: малоземелье фермерских и крестьянских хозяйств, разрушение материально-технической базы АПК, дороговизну новой техники, трудности сбыта, дисбаланс спроса и предложения на рынке сельскохозяйственной продукции и др.

За последние десять лет развитие АПК Молдовы можно охарактеризовать как достаточно нестабильное и чувствительное к влиянию внешних дестабилизирующих факторов. В указанный период наблюдалось снижение доли данного сектора национальной экономики в общем объёме промышленного производства республики с $24 \%$ (2002 г.) до 14\% (2010г.). Несмотря на отрицательную динамику, данный показатель всё же остаётся выше в Молдове, по сравнению со странами Европейского Союза, а также со среднемировым значением.

Таблица 2. Доля АПК в ВВП (\%)

\begin{tabular}{|l|c|c|c|c|c|c|c|c|c|}
\hline & 2002 & 2003 & 2004 & 2005 & 2006 & 2007 & 2008 & 2009 & 2010 \\
\hline Страны ЕС & 2 & 2 & 2 & 1,7 & 1,6 & 1,6 & 1,6 & 1,4 & 1,4 \\
\hline $\begin{array}{l}\text { Республика } \\
\text { Молдова }\end{array}$ & 24 & 21 & 20 & 19 & 17 & 12 & 10 & 10 & 14 \\
\hline В мире & 3,1 & 3,1 & 3,3 & 3,0 & 2,9 & 2,9 & 2,8 & 2,7 & 2,8 \\
\hline
\end{tabular}

Составлено по данным Мирового Банка (http://search.worldbank.org/all?qterm=moldova)

В контексте национальной экономической безопасности, особенно в области продовольственной обеспеченности, первостепенное значение играет сельское хозяйство. Анализ состояния данной сферы в Республике Молдова за последние десять лет позволил выявить ряд существенных проблем, которые могут рассматриваться как угрозы национальной экономической безопасности.

Прежде всего, это высокая нестабильность развития сельского хозяйства. Существенное увеличение годового объёма сельскохозяйственного производства на $32 \%$ (в 2008г) и 18\% (в 2010 г.) не смогло компенсировать потери 2007 и 2009 годов. В 
результате объём сельскохозяйственного производства в 2010г. снизился на 2,1\% в сравнении с 2005г. ${ }^{7}$

Резкие «скачки» в годовом выпуске обеспечили за десятилетие скромный прирост общего объема всей сельхозпродукции - на 7.9\%, в том числе растениеводства - на 4,9 $\%$, животноводства - на 14,1\%.

Другой опасностью, исходящей из аграрной сферы, является весьма низкая урожайность сельскохозяйственных культур. За период с 2005-2010гг. (исключение 2008г.) зарегистрирована отрицательная динамика производительности в сельском хозяйстве, что негативно влияет на продовольственную безопасность, а значит, и на экономическую безопасность Молдовы в целом.

Таблица 3. Средняя урожайность основных сельскохозяйственных культур (ц / га)

\begin{tabular}{|l|c|c|c|c|c|c|}
\hline & 2005 & 2006 & 2007 & 2008 & 2009 & 2010 \\
\hline Пшеница & 26,1 & 23,4 & 13,1 & 31,3 & 20,9 & 26,5 \\
\hline Кукуруза & 32,7 & 28,8 & 7,8 & 34,5 & 28,4 & 34,1 \\
\hline $\begin{array}{l}\text { Подсолнеч } \\
\text { ник }\end{array}$ & 12,0 & 13,2 & 6,7 & 16,3 & 12,5 & 15,2 \\
\hline $\begin{array}{l}\text { Сахарная } \\
\text { свекла }\end{array}$ & 290,1 & 277,8 & 178,6 & 388,9 & 143,0 & 315 \\
\hline Табак & 105,4 & 109,5 & 56,3 & 86,7 & 93,6 & 101 \\
\hline Картофель & 104,4 & 110,8 & 56,9 & 92,5 & 84,4 & 89,2 \\
\hline Овощи & 14,2 & 13,9 & 11,9 & 14,5 & 16,7 & 16,6 \\
\hline
\end{tabular}

7 Статистический ежегодник Республики Молдова, 2011, с.319; (http://www.statistica.md/pageview.php?l=ru\&idc=263\&id=2193) 


\begin{tabular}{|l|c|c|c|c|c|c|}
\hline Фрукты & 36,7 & 31,2 & 26,0 & 35,8 & 31,4 & 33,8 \\
\hline Виноград & 36,0 & 32,0 & 41,0 & 44,4 & 48,2 & 35,0 \\
\hline
\end{tabular}

Составлено по данным Департамента Статистики Республики Молдова (http://www.statistica.md/search.php?go=1\&l=ru\&searchfield)

В течение последнего десятилетия потребление основных продуктов питания на душу населения в Молдове значительно ниже рекомендуемой физиологической нормы. Данное обстоятельство отражает фактическое недопотребление населения, демонстрирует низкий уровень продовольственной безопасности и является очевидной угрозой национальной безопасности.

Таблица 4. Потребление продуктов питания на душу населения (кг)

\begin{tabular}{|l|c|c|c|c|c|c|c|c|c|c|c|}
\hline & $\begin{array}{l}\text { Физиологич } \\
\text { еская норма } \\
\text { потребления } \\
\text { в Молдове }\end{array}$ & $\mathbf{2 0 0 1}$ & $\mathbf{2 0 0 2}$ & $\mathbf{2 0 0 3}$ & $\mathbf{2 0 0 4}$ & $\mathbf{2 0 0 5}$ & $\mathbf{2 0 0 6}$ & $\mathbf{2 0 0 7}$ & $\mathbf{2 0 0 8}$ & $\mathbf{2 0 0 9}$ & $\mathbf{2 0 1 0}$ \\
\hline $\begin{array}{l}\text { Мясо и } \\
\text { мясопроду } \\
\text { кты }\end{array}$ & 44 & 24 & 27 & 27 & 32 & 40 & 38 & 36 & 32 & 30 & 36 \\
\hline $\begin{array}{l}\text { Молоко и } \\
\text { молочные } \\
\text { продукты }\end{array}$ & 240 & 155 & 167 & 164 & 166 & 174 & 177 & 175 & 155 & 169 & 175 \\
\hline Яйца, & 280 & 139 & 158 & 158 & 162 & 177 & 168 & 177 & 141 & 162 & 185 \\
штук & 93 & 65 & 68 & 69 & 63 & 75 & 88 & 59 & 58 & 59 & 57 \\
\hline Картофель & 150 & 104 & 99 & 107 & 88 & 101 & 132 & 76 & 99 & 106 & 110 \\
\hline Овощи
\end{tabular}




\begin{tabular}{|l|c|c|c|c|c|c|c|c|c|c|c|}
\hline Фрукты & 80 & 33 & 38 & 43 & 38 & 37 & 39 & 28 & 41 & 35 & 41 \\
\hline $\begin{array}{l}\text { Хлеб́ и } \\
\text { хлебобулоч } \\
\text { ные } \\
\text { изделия }\end{array}$ & 144 & 139 & 141 & 133 & 146 & 142 & 136 & 119 & 123 & 119 & 117 \\
\hline
\end{tabular}

Составлено по данным Департамента Статистики Республики Молдова (http://www.statistica.md/ pageview.php?l=ru\&id=2278\&idc=315)

* Официальный Монитор Республики Молдова, 2000, №115

В большинстве стран продовольственная независимость считается обеспеченной, если национальное производство жизненно важных продуктов питания составляет не менее $80 \%$ годовой потребности населения, рассчитанной в соответствии с физиологическими нормами питания. Аграрный потенциал Республики Молдова ещё далек от данного стандарта. Об этом свидетельствует и невысокий «душевой» выпуск различных видов сельскохозяйственной продукции.

Таблица 5. Производство основных видов сельскохозяйственной продукции на душу

\begin{tabular}{|l|c|c|c|c|c|c|c|c|}
\hline \multicolumn{1}{|c|}{ населения (кг) } & 2003 & 2004 & 2005 & 2006 & 2007 & 2008 & 2009 & 2010 \\
\hline Зерно & 446 & 831 & 789 & 639 & 252 & 888 & 610 & 680 \\
\hline Подсолнечник & 108 & 93 & 92 & 106 & 44 & 104 & 80 & 107 \\
\hline Сахарная свекла & 182 & 253 & 276 & 328 & 171 & 269 & 95 & 235 \\
\hline Картофель & 84 & 88 & 105 & 105 & 56 & 76 & 73 & 79 \\
\hline Овощи & 100 & 87 & 108 & 132 & 62 & 105 & 86 & 96 \\
\hline Фрукты & 171 & 119 & 107 & 92 & 78 & 104 & 86 & 91 \\
\hline
\end{tabular}




\begin{tabular}{|l|c|c|c|c|c|c|c|c|}
\hline Мясо & 23 & 24 & 24 & 27 & 30 & 22 & 25 & 31 \\
\hline Молоко & 164 & 174 & 183 & 175 & 169 & 152 & 161 & 166 \\
\hline Яйца, штук. & 171 & 185 & 212 & 213 & 197 & 158 & 180 & 202 \\
\hline
\end{tabular}

Составлено по данным: Статистический ежегодник Республики Молдова, 2011 г., стр.326 (http://www.statistica.md/pageview.php?l=ru\&idc=263\&id=2193)

Обобщая результаты проведенного исследования, можно сделать вывод, что из реального сектора экономики исходит целый ряд существенных угроз для национальной безопасности Республики Молдовы. Их нейтрализация предполагает «пакет» мероприятий по модернизации производственного сектора и росту его конкурентоспособности на основе инноваций и внедрения новых технологий.

Стимулированию инновационных процессов будут способствовать:

- разработка общедоступной информационной базы данных относительно приоритетных (в рамках национальной экономики) направлений исследований, источников финансирования, а также условий участия малых и средних предприятий в научных исследованиях и разработках;

- укрепление существующих и создание новых научно-технических парков и инновационных инкубаторов, консалтинговых и инжиниринговых центров, научнотехнических кластеров, технологических платформ и других современных структур инновационной экономики;

- создание консорциумов между высшими учебными заведениями и частными компаниями, специализирующимися в области научных исследований и высоких технологий, что будет способствовать разработке, абсорбции, защите и передачи в социально-экономическую практику научных знаний и высоких технологий, результатов национальных исследований;

- подвижки в системе налогообложения:

- освобождение от налога на прибыль, а также местных налогов и сборов все научно-прикладные разработки и инновационные проекты, включая частное и негосударственное финансирование НИОКР, а также создание и внедрение опытных образцов наукоёмкого оборудования, машин, технологий;

- применение налоговых каникул (в среднем до 3 лет) и введение налоговых кредитов (до 5 лет) при реализации инновационных проектов с участием частных национальных и иностранных инвесторов.

Для устойчивого функционирования АПК экономики актуально своевременное пополнение, обновление и модернизация основных фондов и оборотных средств предприятий в данных отраслях. В этой связи необходимо: 
- расширить доступ сельхозпроизводителей (личных подворий, крестьянских (фермерских) хозяйств и сельскохозяйственных кооперативов) к кредитам по льготной ставке с учётом продолжительности технологического цикла производства сельскохозяйственной продукции;

- развитие системы сельскохозяйственной кредитной кооперации, как между частными предпринимателями, так и между частными предпринимателями и государством.

С целью роста эффективности производства в АПК конструктивно создание и развитие различных форм сельскохозяйственных кооперативов по снабжению, сбыту и переработке сельскохозяйственной продукции.

\section{ЛИТЕРАТУРА}

[1] Абалкин Л., Экономическая безопасность России: угрозы и их отражение // Вопросы экономики. - 1994. - №12. - С. 54.

[2] Архипов А. и др., Экономическая безопасность: оченки, проблемы, способы обеспечения // Вопросыэкономики. - 1994. - №12. - С. 56.

[3] Департамент Статистики Республики Молдова (http://www.statistica.md/search.php?go=1\&l=ru\&searchfield).

[4] Экономическая безопасность. - М.: ЗАО Финстатинформ., - 1998. - С. 12.

[5] Мировой Банк (http://search.worldbank.org/all?qterm=moldova), Статистический ежегодник Республики Молдова, 2011, с. 275, Годовой отчёт Национального Банка Молдовы, 2011, с. 9-37 (http://www.lan.bnm.org/md/annual_report).

[6] Отчёт Министерства Финансов Молдовы по вопросам публичного долга, государственных гарантий и государственного рекредитования, 2011 (http://mf.gov.md/ro/publicdebt/debt/reports).

[7] Статистический ежегодник Республики Молдова, 2011г,, с. 326 (http://www.statistica.md/pageview.php?l=ru\&idc=263\&id=2193).

\section{BEZPIECZEŃSTWO EKONOMICZNE: STAN I ZAGROŻENIA W REPUBLICE MOLDOWA}

Dla krajów w okresie transformacji gospodarczej, problem bezpieczeństwa ekonomicznego nabiera największej wagi. Bezpieczeństwo ekonomiczne jest rozpatrywane jako zdolność narodowego systemu ekonomicznego do efektywnego i trwałego rozwoju. Prawdopodobieństwo wystapienia zagrożenia, a także stopień ich nasilenia określa się za pomocą specjalnych wskaźników - progowych wartości wskaźników bezpieczeństwa. Wychodząc od podstawowych standardów przyjętych parametrów bezpieczeństwa w świecie i UE, w artykule dokonano systemowej analiza porównawczej stanu realnego sektora gospodarki Republiki Mołdowa oraz sformułowano zalecenia, dotyczące zneutralizowania występującego zagrożenia.

Kluczowe słowa: zagrożenie bezpieczeństwa, instytucje władzy, wskaźniki bezpieczeństwa, narodowy system ekonomiczny, niezależność wyżywienia. 


\section{ECONOMIC SECURITY: STATE AND THREATS IN THE REPUBLIC OF MOLDOVA}

The need for security appears as one of the key requirements of the individual, and society as a whole. For countries with economies that are in transition, the problem of economic security is with greatest urgency. Economic security represents the ability of the national economic system for the effective and sustainable development. The concept of threat is a key in determining economic security. In the assessment it is important to have information about the probability of their occurrence and intensity. It is essential to use specific indicators - the thresholds of economic security. Starting from the basic standards of safety parameters adopted in the world and the EU, in the article the comparative system analysis and the evaluation of the relevant macroeconomic indicators of the Republic of Moldova.

Keywords: security, threat, institutions of power, safety indicators, national economic system, food independence

DOI:10.7862/rz.2012.einh.22 